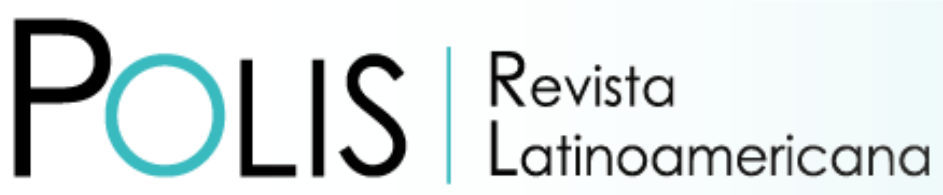

V20 | N59 | 2021

DOI: $10.32735 /$ S0718-6568/2021-N59-1593

\title{
Infiltrados(as) en la academia: capacitismo en la universidad desde la experiencia de académicos(as) con discapacidad/diversidad funcional en Chile
}

\author{
Florencia Herrera Oesterheld \\ Universidad Diego Portales, Santiago, Chile \\ Email: florencia.herrera@udp.cl \\ Luis Vera Fuente-Alba \\ Universidad de Chile, Santiago, Chile \\ Email: lvisvera@uchile.cl
}

Recibido: 20.11 .2020

Aceptado: 18.03.2021

\begin{abstract}
Resumen: El objetivo de este artículo, escrito por dos profesores universitarios con discapacidad, es realizar una primera aproximación al capacitismo existente en las universidades chilenas. Para reflexionar sobre el capacitismo en la academia revisamos experiencias de profesores y profesoras universitarios con discapacidad o diversidad funcional (incluyendo nuestras experiencias). Los(as) profesores(as) enfrentan cargas adicionales de trabajo relacionadas con verse forzados(as) a lidiar con las barreras que les impone el entorno y las actitudes capacitistas. El revelar o comunicar una discapacidad en el ámbito universitario es un proceso complejo. Los riesgos de hacerlo son la estigmatización y la discriminación y no están claras las ventajas. Los(as) académicos(as) con discapacidad/diversidad funcional desarrollan estrategias de resistencia para enfrentar un entorno universitario que los estigmatiza y discrimina. Necesitamos que las universidades modifiquen su infraestructura y su cultura discriminatoria y se transformen en espacios seguros para las personas con discapacidad.
\end{abstract}

Palabras clave: Academia; capacitismo; discapacidad; diversidad funcional; discriminación institucional.

\section{Trespassers in academia: ableism in the university from the experience of academics with disabilities/ functional diversity in Chile}

\begin{abstract}
This paper, written by two university professors with disabilities, aims to provide insight into the ableism present in Chilean universities. To reflect on ableism in academia, we examined the experiences of university professors with disabilities or functional diversity (including our own experiences). Professors face additional workloads related to being forced to deal with barriers imposed by the physical environment and ableist attitudes. Disclosing or communicating a disability in the university setting is a complex process. The risks of doing so are stigmatization and discrimination, and the benefits are unclear. Academics with disabilities/functional diversity develop strategies of resistance to face a university environment that stigmatizes and discriminates. We need universities to modify their infrastructure and discriminatory culture and become safe spaces for people with disabilities.
\end{abstract}


Keywords: Academia; ableism; disability; functional diversity; institutional discrimination.

\section{Infiltrados (as) na academia: capacitismo na universidade a partir da ex- periência de acadêmicos (as) com deficiência/diversidade funcional no Chile}

Resumo: O objetivo deste artigo, escrito por dois professores universitários com deficiência, é fazer uma primeira abordagem ao capacitismo existente nas universidades chilenas. Para refletir sobre o capacitismo na academia, revisamos experiências de professores universitários com deficiência ou diversidade funcional (incluindo nossas experiências). Os professores enfrentam cargas de trabalho adicionais relacionadas ao fato de serem forçados a lidar com as barreiras impostas pelo ambiente e atitudes capacitadoras. Revelar ou comunicar uma deficiência no ambiente universitário é um processo complexo. Os riscos de fazer isso são a estigma e a discriminação e os benefícios não são claros. Acadêmicos com deficiência/diversidade funcional desenvolvem estratégias de resistência a um ambiente universitário que os estigmatiza e discrimina. Precisamos que as universidades modifiquem sua infraestrutura e cultura discriminatória e se tornem espaços seguros para pessoas com deficiência.

Palavras-chave: Academia; capacitismo; deficiência; diversidade funcional; discriminação institucional.

Como citar este artículo:

Herrera Oesterheld, F y Vera Fuente-Alba,L. (2021). Infiltrados(as) en la academia: capacitismo en la universidad desde la experiencia de académicos(as) con discapacidad/diversidad funcional en Chile. Polis Revista Latinoamericana, 20 (59), 99-121. doi: http://dx.doi. org/10.32735/S0718-6568/2021-N59-1593

\section{Introducción}

¿Cómo definirías a alguien que está dentro de un sistema que fue prácticamente diseñado para excluirlo(a)? ¿A alguien que es siempre el(la) único(a), la excepción, el(la) raro(a)? ¿A alguien que debe realizar esfuerzos para ocultar su identidad y simular que sí pertenece? Un(a) infiltrado(a).

El objetivo de este artículo, escrito por dos profesores universitarios con discapacidad visual, es realizar una primera aproximación al capacitismo existente en las universidades chilenas. Para abordar este objetivo nos preguntamos por las experiencias de profesores y profesoras universitarios con discapacidad o diversidad funcional (incluyendo nuestras experiencias). En la primera parte del artículo revisamos algunos conceptos como discapacidad, diversidad funcional y capacitismo (ableism en inglés). A continuación presentamos datos sobre las personas con discapacidad en Chile y su acceso a la educación. Luego revisamos algunos puntos de la Convención sobre los derechos de las personas con discapacidad de Naciones Unidas y argumentamos que el sistema de educación superior excluye a los(as) académicos(as) con discapacidad/ diversidad funcional. 
En la segunda parte del artículo presentamos las experiencias de profesoras y profesores universitarios en torno a tres ejes: 1. la carga extra que implica enfrentarse a las barreras impuestas por el entorno, 2. el 'salir del clóset' o el delicado manejo de cómo, cuándo, a quién y cuánto comunicar respecto de la propia discapacidad y sus dificultades y 3 . las estrategias de resistencia que desarrollan académicas y académicos para enfrentar la discriminación y estigmatización cotidianas.

\section{Evolución del concepto de discapacidad: de la eugenesia a la diversidad funcional}

Los estudios sociales de la discapacidad constituyen un campo de investigación reciente en el norte anglosajón (Oliver, 1998), mientras que en España no se han consolidado (Ferreira, 2008a). Su desarrollo es aún más débil en la región latinoamericana (Brogna, 2009). Actualmente es posible dar cuenta de una diversidad de conceptualizaciones en torno a la discapacidad, las cuales han sido a su vez agrupadas bajo diversos modelos o paradigmas. Palacios y Romañach (2006) refieren la existencia de tres modelos de abordaje de la discapacidad, sucesivos a lo largo de la historia de occidente: el de prescindencia, el rehabilitador y el modelo social.

Siguiendo a estos autores, la primera forma en que fue abordada la discapacidad en la historia de occidente ha sido denominada modelo de prescindencia. En este modelo las causas de la discapacidad tenían un origen religioso, atribuyéndose a las personas con diversidad funcional un carácter diabólico, pecaminoso o ruin, derivado de un castigo divino o consecuencia de pecados parentales. Este modelo tuvo dos manifestaciones históricas: a) la eugenesia, propia de las sociedades militaristas de la antigüedad clásica (el mundo latino y el mundo helénico), en donde se practicaba el infanticidio de los niños con deficiencias; y b) la marginación, propia de la concepción medieval de la deficiencia ligada a prácticas de hechicería u otras cuestiones diabólicas, y el consiguiente menosprecio hacia las personas con discapacidad. Estas eran tratadas como objetos de caridad o bien de temor, derivando en su marginación de la vida social o su relegación a roles como la mendicidad o a servir de objetos de burla.

El modelo biomédico-rehabilitador surge concomitantemente al desarrollo de la ciencia médica moderna y el darwinismo social, y toma fuerza en el periodo de postguerra en el siglo XX. Su objetivo fundamental es la normalización de las personas 'diferentes', aun cuando ello suponga la negación o el ocultamiento de la diversidad funcional, de modo tal que la rehabilitación es un requisito para la incorporación del sujeto en la sociedad (Giaconi, Pedrero y San Martín, 2017). En este contexto de negación de la diferencia, en cuyo marco las causas de la discapacidad se trasladan desde el ámbito religioso al ámbito biomédico, se pasa de la dicotomía 'divino-diabólico' a la dicotomía 'sano-enfermo'. La participación plena en la sociedad sólo es posible a partir de una lógica de asimilación, bajo cuya óptica la diferencia, lejos de ser reconocida, debe ser normalizada. La posibilidad de contribuir a la 
sociedad 'se encontrará supeditada a la rehabilitación o normalización y, esto significa, en definitiva, supeditarlo a que la persona logre asimilarse a los demás --válidos y capaces-- en la mayor medida de lo posible.' (Palacios y Romañach, 2006: 44).

En el contexto latinoamericano y chileno el modelo biomédico - rehabilitador sigue teniendo fuerza y la discapacidad sigue asociada con el estatus de la dependencia, la marginación y la ciudadanía de segunda categoría. Una prueba de esto es la persistencia del principal referente cultural de la discapacidad en Chile desde 1978: la campaña mediática de Teletón y su figura del 'niño símbolo'. La campaña se basa en un discurso asistencialista y caritativo (Ferrante, 2017) que refuerza la 'otredad' de las personas con discapacidad (los 'sanos' deben ayudar a los 'enfermos'). La figura del 'niño símbolo' está marcada por la fragilidad, incompletitud, dependencia, cristiandad y nacionalismo (Humeres, 2016). Así, la campaña se constituye como un dispositivo ideológico del neoliberalismo, actuando como 'fantasía solidarista' (Ferrante, 2017) junto a la cual se desarrolla un mecanismo de soportabilidad de las condiciones de explotación neoliberales.

Un punto de inflexión en el desarrollo de la teorización social sobre la discapacidad se encuentra en el surgimiento de los Disability Studies, que emergieron en Gran Bretaña en la década de 1970. Los Disability Studies agrupan los estudios de académicos(as) con discapacidad y activistas del movimiento de vida independiente que cuestionaron el modelo médico imperante en aquella época.

En 1976 la Union of the Physically Impaired Against Segregation (UPIAS) en Gran Bretaña, definió la discapacidad como una forma particular de opresión social, fundada en la escasa consideración que la sociedad hace de las personas con deficiencias físicas. Se estableció una distinción entre deficiencia -entendida como el diagnóstico biomédico- y discapacidad -entendida como la innecesaria limitación a la participación social que la sociedad contemporánea impone a las personas con deficiencias, al no tener en cuenta las necesidades de todos sus miembros (Oliver, 1998). En estos términos, la discapacidad existe porque vivimos en sociedades construidas por personas no discapacitadas para personas no discapacitadas.

La distinción entre deficiencia y discapacidad que aportó UPIAS es el fundamento del modelo social de la discapacidad: es el entorno el que no ofrece las condiciones para que las personas con discapacidad puedan participar en forma autónoma en las diversas esferas de la vida social, desde la educación y el trabajo, hasta la sexualidad y el ocio. Este modelo, en lugar de buscar normalizar a las personas con discapacidad como el modelo anterior, se centra en el aporte que estas personas pueden hacer a la sociedad y la necesidad de eliminar las barreras que impiden su participación en igualdad de condiciones con las demás personas. Estas barreras van desde lo actitudinal hasta lo arquitectónico (Giaconi, Pedrero y San Martin, 2017; Parchomiuk, 2014). 
El modelo social constituye un dispositivo heurístico que plantea cambiar el foco desde el modelo médico individual de la discapacidad centrado en las limitaciones funcionales de las personas a los problemas causados por los entornos 'discapacitantes' (Barnes, 2007). De acuerdo con Albrecht (1992 en Oliver, 1999) la discapacidad como la entendemos hoy no es un fenómeno universal, sino que es producto de las sociedades capitalistas ya que la opresión que enfrentan las personas con discapacidad está enraizada en las estructuras económicas y políticas del capitalismo, dado que la organización social del trabajo y el mercado laboral requieren personas que puedan trabajar rápido y sin adaptaciones. Con el capitalismo, las personas con discapacidad sufren de exclusión social y económica. Como consecuencia de esta exclusión, la discapacidad se produjo de una forma particular: como un problema individual que requiere de tratamiento médico (Oliver, 1999). Las tendencias 'deshabilitantes' de las sociedades modernas quedan invisibilizadas (Barnes, 2007) y la rehabilitación se transforma en un bien que se puede transar (un commodity). Esto permite que los acercamientos a la discapacidad por parte de los diseñadores de políticas y los profesionales tengan un enfoque individual, enmarcado en la teoría de la 'tragedia personal' (Barnes, 2007).

En el ámbito hispanoamericano, hay un nuevo punto de inflexión en 2005, cuando Javier Romañach y Manuel Lobato proponen el término diversidad funcional en el Foro de Vida Independiente español. Estos autores coinciden con muchas de las críticas efectuadas desde el modelo social respecto de la situación de opresión de las personas con discapacidad en la sociedad occidental. Proponen el término diversidad funcional para alejarse del carácter peyorativo y biomédico que perciben en términos como discapacidad. Miguel Ferreira (2010) plantea que una de las ventajas de la noción de diversidad funcional reside en el hecho de que otorga la posibilidad de rescatar la experiencia concreta de las personas que experimentan la situación de diversidad funcional, constituyendo en este sentido un paso adelante respecto del modelo social anglosajón, cuya contribución se sitúa, para este autor, más bien en el ámbito estructural o macrosocial (Ferreira, 2008b). De acuerdo con Ferreira, el concepto de diversidad funcional reivindica la idea de diversidad en referencia a la (supuesta) normalidad biológica definida desde el paradigma biomédico, situando al cuerpo discapacitado como punto de reflexión prioritario.

Para aludir a los prejuicios y la discriminación que enfrenta la comunidad con discapacidad se ha utilizado el concepto de capacitismo. Este término proviene del inglés ableism y surgió desde los movimientos sociales en las décadas de 1960 y 1970 en Reino Unido y EEUU. Campbell define el capacitismo como:

"Una red de creencias, procesos y prácticas que produce un tipo particular de ser y cuerpo que es proyectado como el perfecto, típico de la especie y, por lo tanto, esencial y plenamente humano. La discapacidad se presenta entonces como un estado disminuido del ser humano." (traducción desde el inglés por los autores del artículo) (Campbell 2001, 44 en Brown, 2020a).

Para los efectos de este artículo, recuperando los aportes del modelo social anglosajón y de la noción de diversidad funcional, hemos decidido utilizar conjuntamente los términos discapacidad y diversidad funcional. Entenderemos que las personas que portan estas 
etiquetas se mueven en entornos capacitistas, donde se presentan una serie de barreras tanto tangibles como actitudinales, configurando un panorama de discriminación institucional (Barnes, 1998). En este marco adquiere relevancia estudiar las experiencias y estrategias de las personas con discapacidad/diversidad funcional.

\section{Estadísticas sobre discapacidad y educación en Chile}

En el Informe Mundial sobre Discapacidad (2011) se estima que un 15\% de la población mundial, equivalente a mil millones de personas, vive con algún tipo de discapacidad. La discapacidad tiene una mayor prevalencia en países de ingresos más bajos y en los quintiles más pobres. El entorno presenta importantes barreras para la participación plena de las personas con discapacidad': estas tienen peores niveles de salud, peores resultados académicos y menor participación económica, con tasas más altas de pobreza y mayor dependencia (Organización Mundial de la Salud; Banco Mundial, 2011 ).

En Chile, el II Estudio Nacional de la Discapacidad (ENDISC II), efectuado por el Servicio Nacional de la Discapacidad (SENADIS) junto al INE en 2015, muestra una prevalencia de la discapacidad de $20 \%$ para la población adulta (18 años y más), y de un 5,8\% para la población entre 2 y 17 años (Servicio Nacional de la Discapacidad, 2016b: 63). La distribución de la población con discapacidad aparece fuertemente segmentada por género: la prevalencia en la población adulta es de 12,9\% entre los hombres y de $20,3 \%$ entre las mujeres (Servicio Nacional de la Discapacidad, 2016b: 65).

ENDISC II muestra una relación clara entre la prevalencia de la discapacidad y el nivel de ingresos de los hogares. La mayor prevalencia de discapacidad se encuentra en el quintil de menores ingresos. El primer quintil cuenta un $25,5 \%$ de personas en situación de discapacidad, mientras que el quinto muestra sólo un $12,4 \%$.

1 Este informe identifica 4 áreas donde se presentan 'obstáculos discapacitadores': 1. Políticas que no toman en cuenta las necesidades de las personas con discapacidad. 2. Actitudes negativas basadas en prejuicios y desconocimiento de los ajustes razonables. 3. Prestación insuficiente de servicios (problemas de accesibilidad, escaso financiamiento, falta de información para servidores públicos, baja participación y consulta a personas con discapacidad). 4. Falta de datos sobre discapacidad y pruebas de qué intervenciones son necesarias y útiles. 


\section{Gráfico 1: \\ Porcentaje de la población adulta con discapacidad por quintil de ingreso autónomo per cápita del hogar}

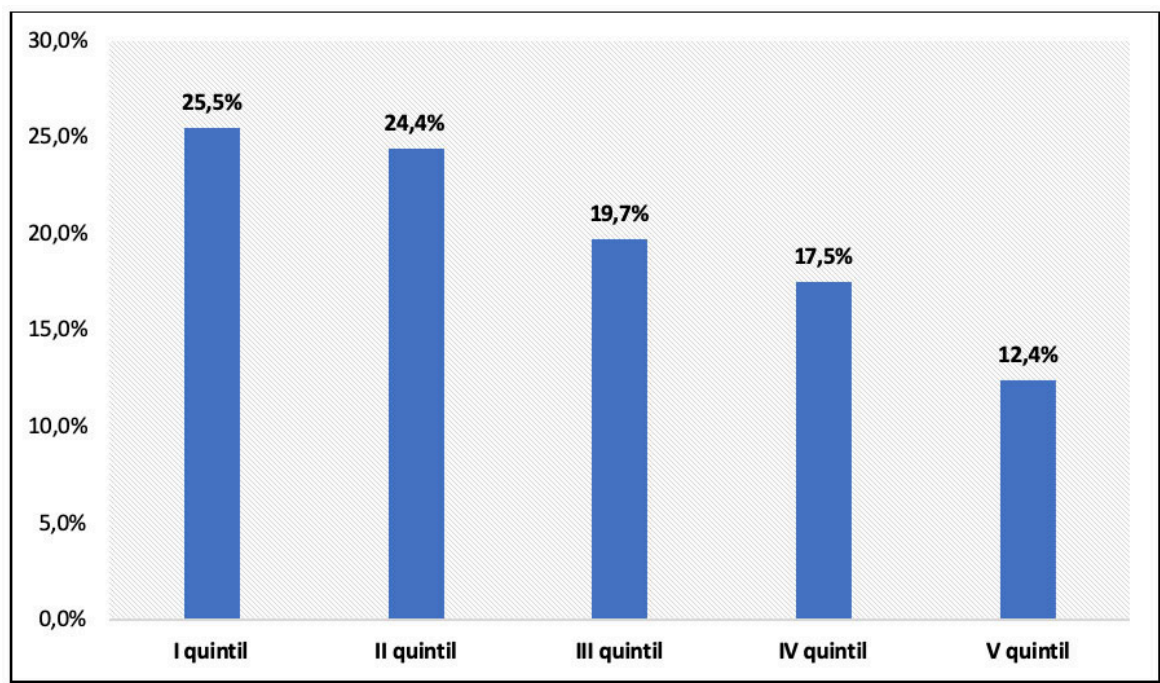

Fuente: elaboración propia en base a datos de ENDISC II

En lo que respecta a la inclusión laboral, los datos del ENDISC II dan cuenta de las condiciones de marginación en las que se encuentra la población con discapacidad a nivel nacional: la población inactiva en este segmento es prácticamente el doble que entre las personas sin discapacidad, equivalente a un $57,2 \%$ contra un $31 \%$. Dicho de otro modo, 6 de cada 10 personas con discapacidad están inactivas, es decir, no trabajan remuneradamente ni buscan trabajo (Servicio Nacional de la Discapacidad, 2016b: 95).

No existen registros respecto de la inclusión de personas con discapacidad/diversidad funcional en la educación superior en Chile, es más, este tema no es considerado en los estudios e informes llevados a cabo para los organismos internacionales (Mella, Díaz, Muñoz, Orrego, y Rivera, 2014; Salinas, Lissi, Medrano, Zuzulich, y Hojas, 2013; Valenzuela, 2016; Zuzulich, Salinas, Achiardi, Hojas, y Pedrals, 2009). No obstante, los datos de ENDISC II en materia de inclusión educativa confirman las brechas detectadas en términos de nivel socioeconómico y grado de discapacidad a nivel general. Las personas con discapacidad /diversidad funcional tienen menos años promedio de estudio que las personas sin discapacidad en cada uno de los quintiles. Sin embargo, la preeminencia del factor socioeconómico queda en evidencia si atendemos al hecho de que el promedio de años de estudio de las personas con discapacidad severa del quintil de mayores ingresos (1 1,5 años) supera el promedio de años de estudio de la población sin discapacidad perteneciente al primer quintil (9.8 años), del segundo quintil (10,1 años) e incluso del tercer quintil (11 años) (ver gráfico 2). 


\section{Gráfico 2 \\ Promedio de años de estudio cursados por la población adulta, por situación y grado de discapacidad}

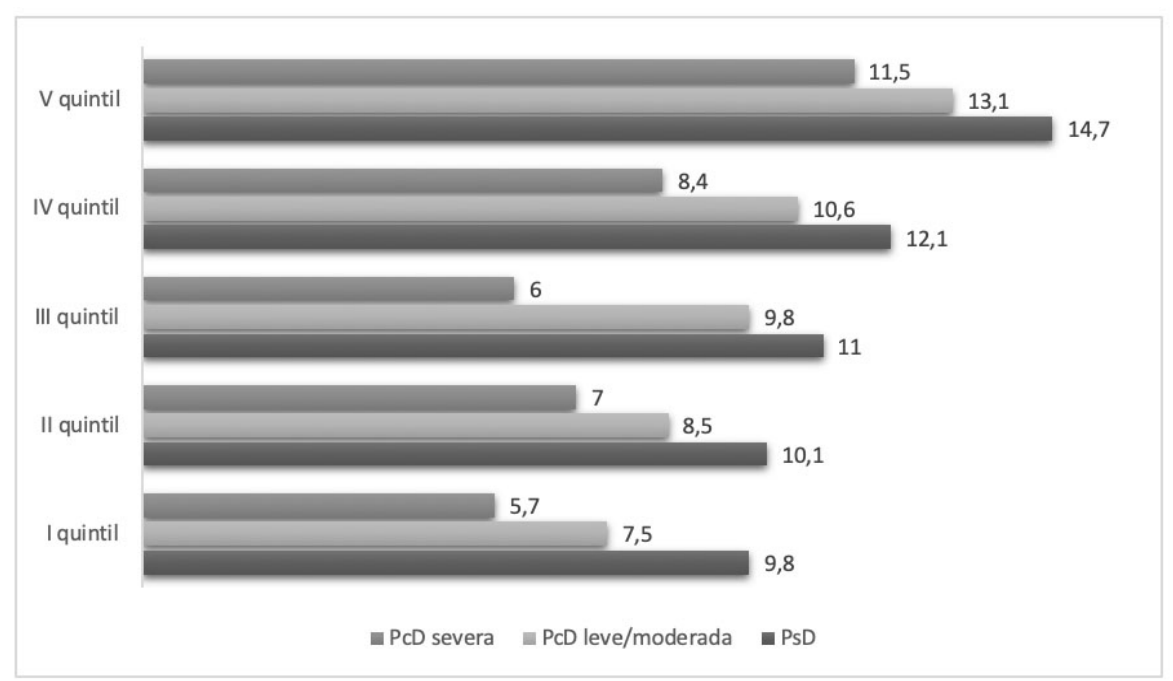

Fuente: elaboración propia en base a datos de ENDISC II

En cuanto al nivel de estudio alcanzado, los datos de ENDISC II expuestos en el gráfico 3 dan cuenta de las enormes brechas que es necesario reducir en materia de educación inclusiva en Chile. Entre la población en situación de discapacidad hay un 7,4\% de personas que no tienen educación formal y un $23,4 \%$ de personas con educación primaria incompleta. Solamente un $9,1 \%$ de las personas con discapacidad tiene estudios superiores (en contraste con el $20 \%$ de la población sin discapacidad) (Servicio Nacional de la Discapacidad, 2016b: 122).

\section{Gráfico 3}

Población adulta por nivel de estudios alcanzado y por situación de discapacidad

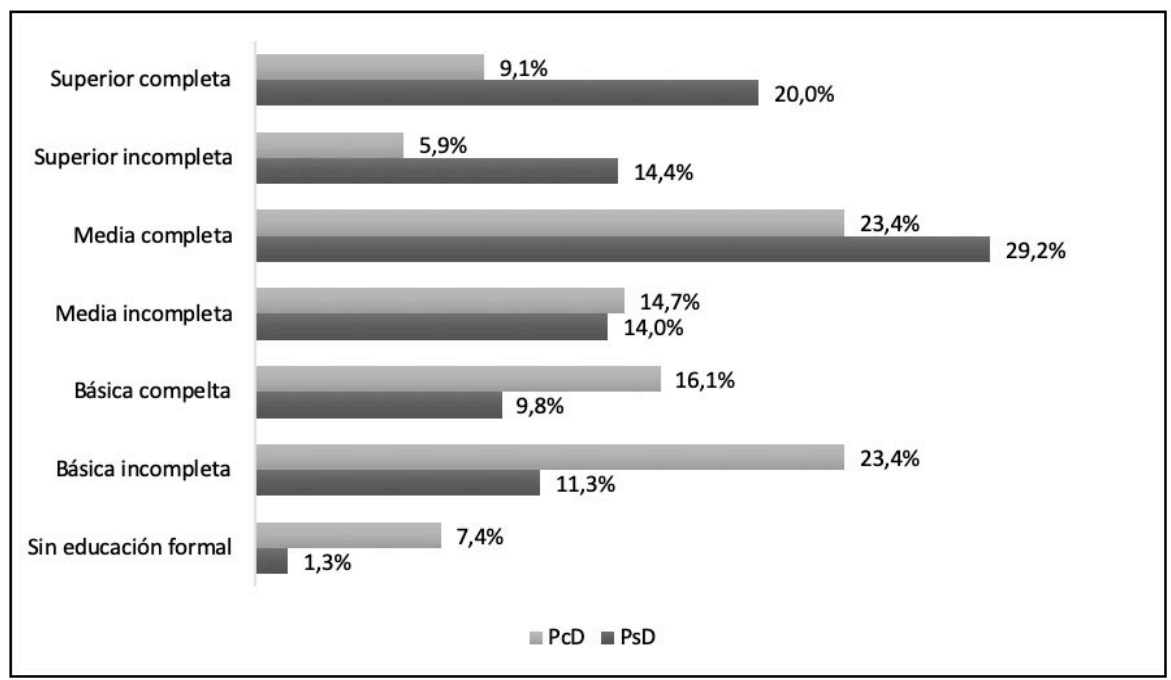

Fuente: elaboración propia en base a datos de ENDISC II 


\section{La Convención sobre los Derechos de las Personas con Discapacidad y el estado del sistema universitario Chileno}

El hito fundamental en la evolución del abordaje de la discapacidad desde el sistema internacional lo constituye la Convención sobre los Derechos de las Personas con Discapacidad (https://www.un.org/esa/socdev/enable/documents/tccconvs.pdf), que fue aprobada por la Asamblea General de Naciones Unidas en 2006. Esta convención constituye el punto culminante de un esfuerzo desarrollado durante décadas por el movimiento social de las personas con discapacidad/diversidad funcional en todo el mundo. Este movimiento buscaba la incorporación dentro de la normativa internacional de una iniciativa que promoviera, protegiera y asegurara el pleno ejercicio de los Derechos Humanos para las personas con discapacidad/diversidad funcional desde una nueva perspectiva, centrada en el cambio de paradigma desde el modelo biomédico hacia el modelo social de la discapacidad (Palacios, 2008). La Convención está estructurada en base a dos conjuntos principales: la igualdad y no discriminación, y la expresión de derechos diversificados para el colectivo de las personas en situación de discapacidad (Cisternas, 2015). El Estado chileno ratificó tanto la Convención como su Protocolo Facultativo en el año 2008.

Los Estados deben rendir cuenta periódicamente al Comité sobre los Derechos de las Personas con Discapacidad sobre las acciones emprendidas para la implementación de los lineamientos de la Convención. Al respecto, el Estado de Chile presentó el año 2012 al Comité un escrito correspondiente al Informe Inicial. En el año 2016 el Comité respondió al Estado chileno con un documento titulado "Observaciones sobre el Informe Inicial de Chile" (Naciones Unidas, 2016). En dicho documento, el Comité manifiesta preocupación sobre diversas materias, entre las cuales se encuentran: la ausencia de una estrategia para una armonización legislativa y la persistencia de términos peyorativos en normas vigentes, incluyendo el Código Civil y la Ley 20.422 (que establece normas sobre igualdad de oportunidades e inclusión social de las personas con discapacidad); la falta de implementación de mecanismos para hacer efectivos los derechos consagrados en la Convención; las restricciones institucionales a dicho ejercicio; la internación psiquiátrica forzosa y prolongada de personas con discapacidad declaradas interdictas; la obsolescencia y disposiciones abiertamente discriminatorias de la legislación civil y penal; la falta de condiciones para el consentimiento informado de las personas con discapacidad, especialmente aquellas declaradas interdictas y respecto de intervenciones médicas invasivas e irreversibles; la persistencia de campañas públicas como Teletón que, recibiendo fondos públicos, difunden imágenes estereotipadas de la población con discapacidad que son contrarias al Enfoque de Derechos; la persistencia de tratamientos crueles y degradantes con el propósito de corregir a personas con discapacidad psicosocial; la existencia de evidencias respecto de la violación a los Derechos Humanos de personas con discapacidad por parte de Carabineros y otros agentes del Estado, entre muchas otras observaciones, totalizando 73 considerandos (Naciones Unidas, 2016). 
La Convención aborda el tema del acceso a la educación superior en el punto 5 del artículo 24:

"Los Estados Partes asegurarán que las personas con discapacidad tengan acceso general a la educación superior, la formación profesional, la educación para adultos y el aprendizaje durante toda la vida sin discriminación y en igualdad de condiciones con las demás. A tal fin, los Estados Partes asegurarán que se realicen ajustes razonables para las personas con discapacidad" (Naciones Unidas, 2006: 20).

La situación de profesoras y profesores universitarios no se aborda explícitamente en la Convención, pero muchos de sus artículos los afectan directamente. En el artículo 27 se aborda el derecho de las personas con discapacidad a trabajar en igualdad de condiciones en entornos abiertos, inclusivos y accesibles. En el punto i) de este artículo se establece que los Estados deben: 'Velar por que se realicen ajustes razonables para las personas con discapacidad en el lugar de trabajo'.

Nicole Brown, en el libro Ableism in Academia, sostiene que en Reino Unido existe un sistema de educación superior neoliberal que se ha marquetizado y burocratizado. Las universidades se han convertido en negocios corporativos que deben mantener su prestigio en el mercado de la educación superior ya que compiten entre sí por atraer estudiantes que puedan financiar sus estudios. Este giro neoliberal ha impactado directamente las carreras, los roles e identidades de académicas y académicos. Por sobre sus compromisos docentes, académicas y académicos están continuamente presionados para que desarrollen investigación de alto nivel, consigan fondos para investigación y publiquen en revistas prestigiosas (Brown, 2020a).

La situación en Chile es similar y la presión ejercida por las universidades chilenas sobre sus académicas y académicos para que aumenten su productividad ha crecido significativamente en los últimos años. Y esta productividad se mide con criterios muy rígidos. Vivimos bajo el imperativo de publicar resultados de investigaciones en revistas indizadas en Web of Science aún cuando esto nos aleje de los lugares donde se están discutiendo los temas que investigamos (Opazo et al, 2019).

Para lograr estos altos estándares de exigencia se requiere ser el 'académico perfecto'. Este 'ser' estandarizado lo encarna el hombre sin discapacidad ni labores de cuidado. Las expectativas en torno a la productividad son tales que la desviación de la norma es prácticamente imposible (Brown, 2020b). El perfeccionismo, la productividad y la eficiencia internalizados en la academia contemplan solo cuerpos normativos, totalmente 'capaces'. De acuerdo con Brown (2020 $)$ el capacitismo en la academia es endémico.

En vez de aprovechar y fomentar la diferencia como un reflejo de la sociedad, los sistemas académicos buscan normalizar y homogeneizar las formas de ser profesor(a) e investigador(a) (Brown 2020). Además, la organización de la academia no favorece la solidaridad y la colaboración si no que se sostiene en la competitividad (por fondos de investigación y 
publicaciones) (Gillberg, 2020). Esta estandarización y competencia excluye a las académicas y los académicos con discapacidad o diversidad funcional. Y los(as) que logramos entrar somos invisibles.

Cuando se discute sobre inclusión en la educación superior suele pensarse solo en la admisión especial para estudiantes con discapacidad / diversidad funcional y los ajustes que serán necesarios para ellos(as). Las universidades se olvidan que podrían tener profesores(as) de tiempo completo o parcial con discapacidad (Gillberg, 2020). Esto deja a estos profesores(as) expuestos a prejuicios y estereotipos capacitistas, con cargas laborales desproporcionadas, y sin la posibilidad de acceder a ajustes razonables.

\section{El capacitismo en la academia}

Para abordar el tema del capacitismo en la academia conversamos con 6 personas con discapacidad/diversidad funcional que trabajan (o trabajaron) en distintas universidades chilenas. Las conversaciones duraron alrededor de una hora y se llevaron a cabo por videoconferencia entre los meses de noviembre de 2020 y marzo 2021. Los temas abordados están relacionados con las experiencias laborales (docencia, gestión, investigación), experiencias de discriminación o inclusión, estrategias de adaptación y resistencia.

En esta sección consideraremos también nuestras propias experiencias como académicos(as) con discapacidad. De esta forma, contamos con las experiencias de 8 personas con discapacidad que hacen o han hecho clases en universidades chilenas. Algunas hacen además investigación y/o tienen cargos de gestión. Estas personas tienen distintos tipos de discapacidad (sensorial, física, psicosocial). Para algunas su condición es de nacimiento y para otras ha sido adquirida a lo largo de la vida. No daremos información sobre la identidad de estas personas ni de las universidades en las que trabajan porque tocamos temas delicados y queremos evitar cualquier potencial perjuicio para los(as) involucrados(as). Por la misma razón no identificaremos los ejemplos que correspondan a nuestra propia experiencia. Todos los nombres que se mencionan son seudónimos.

\section{Carga laboral extra}

Gillberg (2020) sostiene que trabajar en la Universidad en las mismas condiciones y términos que colegas sin discapacidad supone una carga extra para los(as) académicos(as) con discapacidad. Esta carga adicional, no remunerada, se traduce en un peso injusto para los(as) profesores(as) con discapacidad/diversidad funcional. Este punto aparece reiteradamente en las experiencias de los profesores con los que conversamos: el tener una discapacidad/ diversidad funcional supone, en muchos sentidos, una considerable carga de trabajo extra. 
En primer lugar, aparece la carga que supone el tener que lidiar con las barreras evidentes que impone el entorno universitario, usualmente sin acceso a ajustes razonables. Por ejemplo, infraestructuras inaccesibles (falta de ascensores, o ascensores fuera de servicio, señalización no inclusiva, escaleras y desniveles, ausencia de baños inclusivos o baños con llave, etc), sistemas informáticos no inclusivos (información entregada en mails y páginas web no apta para personas con discapacidad visual), conferencias y reuniones sin intérprete de lengua de señas ni subtítulos. En todos estos casos, los(as) profesores(as) deben sortear estos obstáculos usando sus propios recursos y habilidades o exigir a la institución que realice ajustes razonables (que no suelen estar considerados). Las dos opciones suponen destinar tiempo y esfuerzo.

Clara (discapacidad visual) señala que dedica tres veces más tiempo que sus colegas en llenar los formularios de la universidad que están en formatos no accesibles. Sostiene que se encuentra ante la disyuntiva de dedicar tiempo y esfuerzo extra en lidiar con los formularios tal como están o dedicar aún más tiempo y energía a exigir a la universidad que modifique y haga accesibles estos formularios.

Cuando era estudiante de posgrado a Cristina, que tiene movilidad reducida, le asignaron dos cursos consecutivos en dos salas que estaban a una distancia de una cuadra (100 metros aproximadamente). La universidad estaba al tanto de su situación pero no previó que para ella sería imposible desplazarse entre una sala y otra en el tiempo que estaba contemplado (10 minutos). Esto generó frustración en Cristina, quien redactó una carta exigiendo que se cumplieran sus derechos. Es decir, tuvo que dedicar tiempo y energía para poder tener acceso a su sala de clases.

Gillberg (2020) argumenta que la producción de conocimiento inevitablemente se ve perjudicada por las injusticias impuestas a los(as) académicos(as) con discapacidad por las estructuras capacitistas (por ejemplo, horas adicionales no pagadas dedicadas a asegurar el acceso y la inclusión que se requiere para poder desempeñar su trabajo).

En segundo lugar, los(as) profesores(as) se enfrentan a las actitudes discriminatorias de su entorno donde aún no se ha desterrado al modelo biomédico y se entiende la discapacidad como una 'tragedia personal'. De acuerdo con Gillberg (2020), las disciplinas académicas existen dentro de paradigmas de conocimiento capacitistas. Las prácticas discriminatorias se dan en todos los niveles y suelen ser percibidas solo por aquellos(as) que son afectados(as).

Los(as) académicos(as) sostienen que lidiar con las actitudes capacitistas del entorno universitario puede ser emocionalmente agotador. En nuestras conversaciones recopilamos algunas afirmaciones emitidas por autoridades, profesores y funcionarios de universidades chilenas que dan cuenta de miradas donde se devalúa a las personas con discapacidad y se refuerza la idea de un ser normativo y estándar: 'los ciegos no pueden estudiar sociología', '¿para qué vamos a hacer rampas si hay una sola persona en silla de ruedas?', '¿ipor qué aceptamos estudiantes con discapacidad si no estamos preparados?', 'a mí nadie me ha 
enseñado a hacer clases a un estudiante con discapacidad'. Estas afirmaciones reflejan la resistencia de instituciones y funcionarios(as) a hacer adaptaciones y la poca conciencia de la necesidad y relevancia de incluir a personas con discapacidad dentro de la universidad.

Valentina (discapacidad visual) sostiene que 'el ambiente académico es muy excluyente' y 'es súper desgastante el tema de los prejuicios'. Hace algunos años Valentina postuló a un cargo docente. No fue seleccionada. De acuerdo con sus palabras la jefatura a cargo le dijo 'No estamos segura de que tú puedas hacer clases'. En otra universidad a la que también postuló, la preguntaron: '¿usted puede venir con lentes de sol? Es que su cara puede incomodar a los estudiantes.'

Roberto relata que en una entrevista de trabajo en una universidad chilena la autoridad que lo estaba entrevistando le preguntó: '¿qué problemas le traerá tu discapacidad a la universidad?'. Esta pregunta refleja cómo la discapacidad no es entendida como una diferencia que enriquece sino todo lo contrario, como una falla que traerá dificultades para la institución.

Para contrarrestar estos prejuicios y actitudes discriminatorias, los(as) profesores(as) sienten que deben estar continuamente demostrando que son capaces: 'es agotador estar siempre demostrando que uno se la puede' sostiene Camilo. Esto perjudica las posibilidades de solicitar ajustes razonables, ya que podría ser leído como una forma de mostrar vulnerabilidad. Leigh y Brown (2020) argumentan que las formas de trabajar en la academia están tan internalizadas que las personas se sienten comprometidas y obligadas a encajar con las normas existentes. Valentina (discapacidad visual) afirma que aunque 'uno se demora mucho más en las cosas que tiene que hacer' ella nunca pide extensión en los plazos.

En tercer lugar, los profesores(as) con discapacidad/diversidad funcional con quienes conversamos adquieren responsabilidades extra ligadas a trabajar para que la universidad sea un espacio más accesible e inclusivo. Esto conlleva, nuevamente, enfrentar una cultura capacitista y discapacitante, que presupone cuerpos y mentes normativas.

A Roberto, por ejemplo, le preocupa que la universidad sea un espacio donde potenciales estudiantes con discapacidad se sientan seguros(as) e incluidos(as). Con este fin ha agregado un ítem de apoyo a estudiantes con discapacidad en los programas de los cursos que imparte y está trabajando para que la bibliografía obligatoria esté en formato de audiolibro. Sin embargo, la primera iniciativa la ha realizado a espaldas de las autoridades ya que la universidad establece que todos los programas de cursos deben ser iguales. Y la segunda iniciativa ha encontrado resistencia por parte de las autoridades porque consideran que escuchar un libro en vez de leerlo es 'cosa de flojos'.

Al ser las únicas personas con discapacidad en sus espacios de trabajo varios profesores(as) señalan que sienten que se han transformado en 'niños símbolo' o en íconos de la discapacidad en sus universidades. Algunas universidades cuentan con unidades o departamentos 
de inclusión pero todas sus acciones están dirigidas a los(as) estudiantes. Guillermo (discapacidad psicosocial) afirma 'las universidades han tenido que abrirse a la inclusión, pero no nos consideran a nosotros, la inclusión está vista como un tema de asuntos estudiantiles, no como un tema de comunidad'. El 2017 se dictó la Ley № 21.015 que establece que el $1 \%$ del personal contratado por todas las empresas con más de 100 empleados deben ser personas con discapacidad. A raíz de esta ley casi todos los(as) profesores(as) con los que conversamos fueron contactados por sus empleadores y presionados para que se inscribieran en el Registro Nacional de Discapacidad. En ninguno de los casos se les había ofrecido apoyo o ajustes razonables antes o después de contactarlos para contemplarlos como parte del $1 \%$. El espíritu de la ley es fomentar el ingreso al mercado laboral de personas con discapacidad/diversidad funcional, sin embargo, las universidades se volcaron a buscar trabajadores con discapacidad ya contratados para no tener que enfrentar costos extra. Camilo tiene claro que la discapacidad está lejos de ser una prioridad en su universidad, menos aún el cumplimiento de la ley de inclusión laboral:

\begin{abstract}
"Aquí hay incluso una Política de Discapacidad, promulgada con bombos y platillos, en una pomposa ceremonia. No obstante, en Recursos Humanos contrataron a una persona con discapacidad para hacer un diagnóstico de la inclusión laboral, pero después de hecho ese trabajo la persona fue desvinculada. Ya saben que hay trabajadores con discapacidad, docentes y no docentes, pero no están dispuestos a invertir recursos en proveer las adecuaciones y apoyos que requieren."
\end{abstract}

Los sistemas estandarizados de evaluación, calificación y jerarquización diseñados pensando en el cuerpo normativo (no diferente) no consideran que los(as) académicos(as) con discapacidad/diversidad funcional deben soportar cargas de trabajo más pesadas que sus colegas sin discapacidad. Los altos niveles de exigencia y competitividad tienen como efecto que los(as) profesores(as) con discapacidad deban dedicar muchas más horas de trabajo que las establecidas en sus contratos para alcanzar las mismas metas que sus colegas sin discapacidad. Aun así, es difícil alcanzar los altos niveles de productividad exigidos en término de publicaciones o acceso a fondos de investigación competitivos (Griffiths, 2020). Valentina argumenta: '[los profesores con discapacidad] estamos en una super desventaja en la postulación de proyectos'. Un entorno capacitista menosprecia las capacidades de los(as) profesores(as) con discapacidad a la vez que invisibiliza las dificultades que enfrentan.

\title{
'Salir del clóset' de la discapacidad
}

En inglés el término usado por la literatura para revelar una discapacidad al entorno es disclosure. Este concepto está usualmente asociado a revelar discapacidades invisibles (como enfermedades crónicas) (Brown, 2020b; Gillberg, 2020). En base a nuestras conversaciones con profesores(as) con discapacidad estimamos que la expresión 'salir del clóset', usualmente usada para revelar una identidad no heterosexual, es una metáfora que permite dar cuenta de la experiencia de revelar una discapacidad al entorno -que implica la revelación de una identidad estigmatizada (Goffman, 1963). Además, consideramos que 
esta comunicación aplica a todas las condiciones, sean visibles o invisibles para el entorno. Todas las personas con discapacidad deben tomar decisiones respecto a cómo, cuándo, a quién y cuánto comunicar respecto de la propia discapacidad y sus dificultades. No estamos hablando solo de momentos dramáticos de revelación. El manejo comunicacional suele ser un proceso que las personas con discapacidad enfrentan todos los días. Continuamente debemos estar decidiendo entre intentar disimular la dificultad que enfrentamos o comunicarla (y eventualmente solicitar ajustes o asistencia).

Gillberg (2020) señala que 'salir del clóset' para los(as) académicos(as) con discapacidad es una espada de doble filo que involucra una red intrincada de negociaciones que rara vez tiene un resultado positivo para la carrera académica. El 'salir del clóset' implica riesgos y muchas veces las ventajas de 'disimular' la discapacidad y las dificultades que conlleva son mayores que las ventajas de comunicarlas (Brown, 2020b; Martin, 2020). Brown (2020b) explica que para acceder a los beneficios asociados a la discapacidad en Reino Unido (apoyo, ajustes razonables, beneficios económicos o subsidios) los(as) académicos deben 'salir del clóset'. Sin embargo, usualmente comunicar una discapacidad conlleva ser catalogado como una persona desviada de la sociedad normalizada y, por lo tanto, aumenta el riesgo de ser estigmatizado(a) y discriminado(a) (Brown, 2020; Goffman, 1963). Martin (2020) agrega que un riesgo de 'salir del clóset' es que tu identidad sea reducida a la discapacidad (entendida como limitación) oscureciendo otros aspectos de la persona.

Para muchos(as) académicos(as) los riesgos son demasiado grandes y prefieren disimular e intentar que su discapacidad pase desapercibida mientras les sea posible. Al respecto Guillermo (discapacidad psicosocial) sostiene:

"Yo estuve dentro del clóset muchísimos años, ni mi mejor amigo sabía (...) Lo viví muy duro, en términos de lo que es estigma, o sea, el estigma no es que lo tengas en la frente y la gente lo vea, lo tienes en la frente y tú lo sientes y tú sientes que si llegas a develarlo la expectativa es que vas a ser desacreditado. La desacreditación por tener un trastorno psicosocial es muy fuerte."

Para los profesores con discapacidad con los que conversamos, 'salir del clóset' es una decisión difícil ya que suele tener un impacto negativo en las oportunidades laborales. Los(as) que tienen condiciones degenerativas (que se van agravando con el tiempo) sostienen que disimularon su condición y las dificultades asociadas todo lo que les fue posible. En términos concretos esto supone, por ejemplo, simular que uno está viendo algo cuando no lo ve o que está escuchando algo que no escucha. Los profesores lo describen como una experiencia estresante. Francisca afirma: 'me hicieron esconder mi sordera'. Los profesores(as) se sienten presionados a minimizar los desafíos que enfrentan y presentar un comportamiento optimista (Martin, 2020). Alejandro, académico con diversidad funcional del área de la salud que tiene una condición visual degenerativa, se define como un 'infiltrado en el mundo de la policía del cuerpo'. Cuenta que cuando llegó a la especialidad en visión de su carrera se encontró con una académica que lo había tratado y que ésta le dijo 'tú no puedes estar aquí.' 
Brown (2020b) sostiene que para tener la confianza necesaria para marcar la opción 'tengo una discapacidad' en un formulario se requiere haber recorrido un camino de autoaceptación, es decir, aceptar que la discapacidad es una experiencia normal en la vida, esto es difícil ya que va en contra de lo establecido por los entornos capacitistas. Para el entorno, comunicar una discapacidad equivale a admitir una debilidad y mostrarse vulnerable. Admitir debilidad es peligroso en un ambiente laboral con contratos precarios e inseguridad laboral (como es el caso de la academia en Chile). Valentina (discapacidad visual) sostiene que en el ambiente laboral siempre tiene miedo. La decisión de comunicar o disimular una discapacidad es un acto de autopreservación, control de información y gestión de impresiones. Se trata de manejar cómo se presenta la propia identidad a los demás. 'Salir del clóset' puede ser interpretado como un acto de representación donde inmediatamente se vincula la vida personal a la vida pública (Brown, 2020b). Cuando terminó su doctorado y volvió a Chile, Roberto decidió contribuir a la representación de los(as) académicos(as) con discapacidad e incluir en sus postulaciones a universidades que tenía discapacidad visual. Ahora cree que esto puede haber dificultado su contratación. Martin (2020), quien realizó una investigación con académicos(as) sobre capacitismo en la educación superior en Reino Unido, señala que muchos de sus participantes sienten que los riesgos de revelar una discapacidad superan las ventajas, especialmente si no hay asistencia disponible.

Desde que empezó a trabajar en la universidad Clara comunicó a sus jefes, colegas, administrativos y estudiantes que tenía una condición visual degenerativa y que, por lo tanto, veía muy poco. Sin embargo, al no usar una asistencia visible (como un bastón) nadie parecía comprender realmente las barreras a las que se enfrentaba. Relata que probó distintas maneras de comunicarlo: 'veo super mal'; 'veo muy poco', 'tengo baja visión', 'tengo discapacidad visual'. Decidió organizar una reunión para explicar en qué consistía su condición y convocó a sus jefes y colegas. Clara relata que esta decisión fue compleja pues implicó exponer aspectos de su vida personal y presentarse como una persona vulnerable. Lo más difícil para ella era que sus colegas la vieran con lástima. "Lo más duro es que te pobreciteen", afirma. La lástima es una forma de estigmatización y discriminación ya que le quita agencia a la persona que es objeto de ella. En la reunión, para explicar claramente su baja visión, presentó algunos de sus exámenes médicos. Tuvo una respuesta positiva por parte de sus colegas, quienes se abrieron y parecieron comprender mejor su situación y de las autoridades, quienes le ofrecieron apoyo. Sin embargo, al poco tiempo, al conversar sobre los cursos que realizaría el siguiente año, su jefatura le indicó que pensaban asignarle cursos de primer año, que implican conocimientos más generales y básicos, ya que pensaban que ella no podría mantenerse actualizada para dictar cursos más avanzados. Clara tuvo que explicarle que no tenía problemas para mantenerse actualizada en su área de docencia e investigación. En este caso, el comunicar su discapacidad llevó a que se subestimara su capacidad como docente. 
Brown (2020b) sostiene que en ambientes capacitistas como el académico existe una falta de conciencia y comprensión de las distintas formas de vivir y trabajar. De acuerdo con Finesilver, Leigh y Brown (2020) los(as) académicos(as) con discapacidad están continuamente tratando de cumplir las expectativas mientras negocian las especificidades del propio cuerpo.

La discapacidad no se vive como un estado fijo, si no fluctuante y fluido. La misma persona puede ir pasando por distintas etapas en su vida o estar teniendo un buen o un mal día. El manejo de la información que se comunicará al entorno conlleva seleccionar qué se comunica, en qué momento, bajo qué circunstancias, a quién, con cuánto detalle. Factores externos como cuán abierto a la diferencia sea el entorno o el tipo de contrato (nivel de seguridad laboral) influirán en cómo se controlará la información de la propia discapacidad. Como la gestión de la información requiere delicadas planificaciones de la puesta en escena de la propia identidad (qué mostrar, qué ocultar), debe ser comprendido como un tipo de trabajo emocional (Brown, 2002b). Este trabajo emocional se suma a las cargas extra mencionadas en la sección anterior.

Los(as) profesores(as) con los(as) que conversamos relatan que en los cursos que imparten dedican un espacio para comunicar y explicar a sus estudiantes su discapacidad/diversidad funcional y las dificultades que conlleva. Este espacio usualmente es en la primera clase, pero también la información debe ser reforzada a lo largo del curso. Francisca (discapacidad auditiva) sostiene que les recuerda constantemente a sus estudiantes que es sorda y que deben hablar fuerte y claro para que ella pueda entenderlos(as). La invisibilidad y baja representación de los(as) profesores con discapacidad en las universidades hace que esta sea una experiencia extraordinaria para los(as) estudiantes: un(a) profesor(a) exponiendo sobre su vida personal, sobre sus dificultades y sobre cómo los(as) estudiantes pueden ayudarlo(a). Roberto argumenta que "para los estudiantes es muy bueno ver que tienen un profesor con discapacidad', les entrega un modelo positivo a los estudiantes en general y facilita la integración de estudiantes con discapacidad en la universidad. Al respecto, Camilo (discapacidad visual) sostiene:

"Cuando yo era estudiante de pregrado siempre quise 'pasar piola', pero tal vez si hubiese tenido al frente a un profe ciego o con baja visión me habría planteado la posibilidad de salir del closet, o habría sentido menos ansiedad y menos miedo al rechazo al pensar en ello."

Alejandro dicta un curso en el que invita a profesores con discapacidad a exponer:

"Nosotros sólo tenemos invitados con diversidad funcional en el curso, y eso hace que los estudiantes que no han salido del closet se vean incentivados a hacerlo, y comienzan a abrirse a compartir sus experiencias en la clase. Para esto es importante crear ambientes protegidos." 


\section{Estrategias de resistencia frente al estigma}

De acuerdo con Frederick (2017), gran parte de la investigación social sobre discapacidad se ha planteado desde el marco del estigma (Goffman, 1963). El estigma es el concepto social dominante ocupado para dar cuenta de los prejuicios y la discriminación que afectan a las personas con discapacidad. El problema es que esta literatura ha tendido a retratar a las personas con discapacidad como víctimas, dejando poco espacio para explorar cómo estas personas rechazan la devaluación cultural de sus identidades. Frederick (2017) propone reconocer la agencia de las personas con discapacidad y estudiar cómo resisten y desafían el estigma.

Las personas con discapacidad/diversidad funcional desarrollan estrategias cotidianas de resistencia para contrarrestar las visiones negativas sobre su discapacidad y evitar la discriminación (Frederick, 2017). Estas estrategias pueden ir desde presentar una imagen pública altamente disciplinada (ser personas sobreadaptadas) a tácticas de 'distanciamiento' (disengagement) que les permiten cerrarse a la posibilidad de ser agredidos(as) (anticipando la discriminación). El 'salir del closet' en el entorno laboral o intentar minimizar las dificultades impuestas por las barreras del entorno también pueden ser leídos como estrategias de resistencia. Estas estrategias se llevan a cabo cotidianamente con altos costos emocionales y físicos. El desarrollo y efectividad de estas estrategias conlleva un arduo trabajo oculto, porque, para que sean efectivas, el esfuerzo para llevarlas a cabo no debe ser visible para el entorno (Frederick, 2017). Es importante considerar que las estrategias desarrolladas para resistir el estigma dependen de marcadores de clase, privilegio y marginalización.

Las estrategias de resistencia que identificamos en las conversaciones con académicos(as) con discapacidad/diversidad funcional pueden clasificarse en: i) estrategias de resistencia que implican adaptación al entorno, ii) estrategias de resistencia que implican ir en contra de las expectativas del entorno, iii) estrategias de resistencia que conllevan actos de representación.

i) En el primer grupo están todas las acciones y prácticas con las cuales los(as) académicos(as) buscan protegerse del estigma a través de adaptarse a las condiciones que les impone el entorno. En estos casos, los(as) profesores(as) disimulan y minimizan las dificultades que les significan las barreras y buscan realizar ellos mismos las adaptaciones para desarrollar su trabajo. Camilo, por ejemplo, sostiene que él mismo traspasa los textos vinculados a su trabajo a audio. Clara sigue esforzándose para llenar formularios no adaptados y, además, se ha resignado a mantener un contrato de media jornada (ninguno de los profesores con los que conversamos tenía contrato jornada completa). Para ella esta es su principal estrategia de adaptación ya que considera que sería demasiado difícil sostener las exigencias vinculadas a docencia e investigación asociadas a una jornada completa. Esto significa que el sueldo de Clara es significativamente menor que el de sus colegas. Cristina y Guillemo sostienen que ha creado redes (informales) de apoyo y equipos de trabajo de manera de construir espacios protegidos. 
ii) En el segundo grupo están las acciones y prácticas que pueden considerarse disruptivas, que desafían lo que se espera de un(a) académico(a) o de una persona con discapacidad. Cristina señala que no acepta un 'no' o un 'no se puede' por respuesta cuando está solicitando ajustes razonables. Ha estudiado la legislación y está dispuesta a exigir sus derechos. Roberto afirma que decidió 'ser rebelde' e ir en contra de las expectativas de la universidad cuando lo contactaron para que se inscribiera en el Registro Nacional de la Discapacidad. Decidió que si se inscribe en el registro será por un proceso y decisión personal, no para avalar las prácticas poco inclusivas de su universidad.

iii) En el tercer grupo están todas las acciones y prácticas que buscan visibilizar la posición de los(as) profesores(as) con discapacidad. Varios profesores(as) señalaron que buscan participar activamente en distintos espacios para 'estar ahí como sujeto diferente' (Roberto). Francisca exigió mascarillas adaptadas para todo el equipo con el que trabaja para poder leerles los labios. Clara relata cómo en un congreso, cuando le tocaba exponer, bajó muy lentamente las escaleras de un auditorio particularmente inaccesible de forma que todos pudieran darse cuenta de su dificultad y de lo inadecuado del espacio físico que estaban habitando. Camilo participa activamente de todas las actividades vinculadas a la temática en su institución, y plantea:

"Al haber estudiado dos carreras de pregrado en la misma institución sin haber tenido adecuaciones, por miedo a salir del closet, ahora que trabajo aquí siento que tengo una especie de legitimidad para plantear las exigencias de accesibilidad y otras como un deber de la institución, no como un favor."

El que los(as) profesores(as) se presenten ante sus estudiantes como personas con discapacidad también puede leerse como actos de representación que trastocan las nociones capacitistas de la discapacidad/diversidad funcional. Contrarrestando una visión de dependencia e infantilización, el(la) docente -una persona con discapacidad- se posiciona en el lugar de la autoridad, de la persona que está a cargo, de la persona que transmite conocimiento.

\section{Conclusiones}

Las experiencias de los(as) académicos(as) con discapacidad/diversidad funcional permiten confirmar la preeminencia en las universidades chilenas de una perspectiva capacitista, basada en los presupuestos individualistas de la 'teoría de la tragedia personal' o modelo biomédico de la discapacidad/diversidad funcional. Se evidencia, además, la presencia de reminiscencias eugenésicas, dado el carácter excluyente, discriminatorio y hostil del ambiente laboral universitario para quienes pertenecemos a este colectivo en el mundo académico. Es desalentador constatar que estos rasgos eugenésicos continúan configurando la discriminación institucional (Barnes, 1998) de las personas con discapacidad/diversidad funcional en el mundo del quehacer universitario. La universidad ha normalizado formas específicas de producción de conocimiento y maneras particulares de trabajar y enseñar que consideran que la discapacidad no es apropiada (Griffiths, 2020). Como señala Brown (2020a), el capacitismo en la academia es endémico. 
El sistema universitario neoliberal basado en la competencia esconde las ventajas ofrecidas a unos pocos que se ajustan a la norma (hombres, sin discapacidad ni labores de cuidado) bajo principios como la estandarización y la productividad. Al mismo tiempo, invisibiliza las dificultades que enfrentamos las personas que estamos fuera de la norma e impide que personas con discapacidad/diversidad funcional ingresen y aporten al desarrollo de las diversas disciplinas del conocimiento.

Creemos que la situación de los(as) académicos(as) con discapacidad/diversidad funcional requiere de más atención y estudio en Chile y Latinoamérica. En este artículo realizamos una primera reflexión en torno a las experiencias de un grupo pequeño de profesores universitarios en Chile. Probablemente los hallazgos presentados aquí son aplicables a contextos universitarios de otros países latinoamericanos. Para confirmarlo y para conocer las particularidades de cada país es necesario realizar más estudios. Estimamos que futuras investigaciones deberían profundizar en algunos de los temas que aquí abordamos con grupos mayores y más diversos de profesores. Específicamente, nos parece relevante estudiar cómo los marcadores de clase, privilegio y marginalidad afectan las cargas laborales, el control de la información y las estrategias de resistencia al estigma de profesores con discapacidad/diversidad funcional. Es posible que la situación de profesores con discapacidad que además pertenecen a algún otro grupo marginado (por ejemplo, con relación a el género, la clase, la etnia, o la orientación sexual) sea aún más compleja.

Desde nuestro punto de vista, las reflexiones presentadas en este artículo conducen necesariamente a reivindicar la necesidad de acciones afirmativas que permitan incrementar de manera radical la presencia de personas con diversidad funcional en los cuerpos académicos de las instituciones de educación superior. Es urgente no sólo el fortalecimiento, la asignación de presupuestos suficientes y la institucionalización de las incipientes y débiles iniciativas que algunas instituciones han emprendido en materia de inclusión de estudiantes con discapacidad/diversidad funcional, sino su ampliación hacia los demás estamentos de las comunidades universitarias, especialmente al académico.

Las acciones afirmativas a emprender deben ir acompañadas necesariamente de un adecuado sistema de apoyos, adecuaciones y ajustes razonables. Un punto fundamental dice relación con la formalización de los procedimientos para el otorgamiento de estos ajustes y adecuaciones, de modo que los mismos dejen de estar librados a la discrecionalidad o 'buena onda' de personas particulares.

La invisibilidad y baja representación de académicos(as) con discapacidad/diversidad funcional en las universidades es un indicador de lo excluyente que es todo el sistema educativo. Las universidades deben reflejar la diversidad de la sociedad y para ello deben abrirse a recibir académicos(as) con discapacidad/diversidad funcional. El recibirlos(as) pasa por transformar infraestructuras y culturas marcadas por lógicas discriminatorias de carácter capacitista. Estas transformaciones deben realizarse de manera anticipada al ingreso de personas con discapacidad al sistema universitario. Hasta el momento, las modificaciones 
y ajustes se realizan contingentemente, cuando aparece una persona con diversidad funcional. Esto da paso a afirmaciones como 'para qué vamos a hacer una rampa si hay una sola persona en silla de ruedas'. Las universidades deben contar con infraestructura accesible, mecanismos adecuados de apoyo y provisión suficiente de ajustes razonables para crear un entorno que de la bienvenida a las y los académicos con discapacidad/diversidad funcional. Asimismo, se deben eliminar los riesgos y aumentar las ventajas de 'salir del clóset' para que académicos(as) con discapacidad sientan que la universidad es un espacio seguro.

La ausencia de profesores(as) con discapacidad/diversidad funcional en el mundo académico empobrece a las comunidades universitarias, ya que se pierde la riqueza que yace en la convivencia en la diversidad. Esto tiene implicancias epistemológicas relevantes, en la medida que se reproduce la lógica capacitista, no sólo en la discriminación institucional anotada más arriba, sino además en la construcción del conocimiento y la formación de profesionales, artistas e intelectuales, cuyos procesos formativos están construidos sobre la base de supuestos normalizadores. Estos profesionales están siendo preparados para desempeñarse en un mundo supuestamente poblado de personas 'normales', estandarizadas, productivas, capacitadas. Este es uno de los factores que explica la continua reproducción de los prejuicios capacitistas en nuestra sociedad. Como anota Gillberg (2020: 18), los y las académicas son generadores y transmisores de conocimiento y cultura, y por lo tanto, actores centrales de la sociedad, de manera que si quienes desempeñan ese papel no reflejan la diversidad presente en la sociedad, estamos construyendo y reproduciendo un conocimiento marcado por las huellas del capacitismo, que contribuye a su perpetuación en la sociedad.

Queremos dejar de ser la excepción, queremos dejar de ser infiltrados(as) en la academia. Necesitamos una universidad pensada desde el acceso universal, que acoja, respete y valore la diversidad.

\section{Agradecimientos}

Queremos agradecer sinceramente a los y las profesoras que compartieron sus experiencias con nosotros.

\section{Bibliografía}

Barnes, C. (1998). "Las teorías de la discapacidad y los orígenes de la opresión de las personas discapacitadas en la sociedad occidental". En: Barton, Len (Comp.) Discapacidad y Sociedad. Madrid, Morata. Pp. 59-76.

Barnes, C. (2007) "Disability Studies: What's the point?" Intersticios: Revista Sociológica de Pensamiento Crítico. Vol.1 $1 \mathrm{~N}^{\circ} 1$.

Brogna, P. (Comp.) (2009). "Las representaciones de la discapacidad: La vigencia del pasado en las estructuras sociales presentes". En Visiones y Revisiones de la Discapacidad, México, Fondo de Cultura Económica. Pp. 157-186. 
Brown, N. (2020a) "Introduction: Theorizing ableism in academia" en Ableism in Academia: Theorising experiencies of disabilities and cronic illnesses in higher education editado por Brown, N. y Leigh, J. UCL Press: London.

Brown, N. (2020a) "Disclosure in academia: A sensitive issue" en Ableism in Academia: Theorising experiencies of disabilities and cronic illnesses in higher education editado por Brown, N. y Leigh, J. UCL Press: London.

Cisternas, M. S. (2015). "Desafíos y avances en los derechos de las personas con discapacidad : una perspectiva global". Anuario de Derechos Humanos, №11, pp. 17-37. DOI: 10.5354/0718-2279.2015.37486

Ferrante, C. (2017). "El éxito de la Teletón en Chile: paradoja y mensaje en la era de los Derechos". Onteaiken. Boletín Sobre Prácticas y Estudios de Acción Colectiva, $\mathrm{N}^{\circ} 23$, pp. 44-59.

Ferreira, M. (2010). "De la minus-valía a la diversidad funcional: un nuevo marco teórico-metodológico". Política y Sociedad, Vol. 47, N¹, pp. 45-65.

Ferreira, M. (2008a). "Sociología, discapacidad y diversidad funcional: Un mundo diverso pero excluyente". JORNADAS DE SOCIOLOGÍA: Sociología y Tecnología ¿qué Futuro Nos Espera?, 1-7. Recuperado el 20/10/2019 de: http://www.um.es/ discatif/TEORIA/AMSO8_Ferreira.pdf

Ferreira, M. (2008b). "Una aproximación sociológica a la discapacidad desde el Modelo Social: Apuntes caracteriológicos". Revista Española de Investigaciones Sociológicas, N¹24. Pp. 141-174.

Finesilver, C., Leigh, J. N. Brown (2020) "Invisible disability, unacknowledged diversity" en Ableism in Academia: Theorising experiencies of disabilities and cronic illnesses in higher education editado por Brown, N. y Leigh, J. UCL Press: London.

Frederick. A. (2017) "Visibility, Respectability, and Disengagement: The Everyday Resistance of Mothers with Disabilities." Social Science y Medicine, Vol. 181, pp. 131138 doi: https://doi.org/10.1016/j.socscimed.2017.03.030

Gillberg, C. (2020) "The significance of crashing past gatekeepers of knowledge: Towards full participation of disabled scholars in ableist academic structures" en Ableism in Academia: Theorising experiencies of disabilities and cronic illnesses in higher education editado por Brown, N. y Leigh, J. UCL Press: London.

Griffiths, E. (2020) "'But you don't look disabled': Non-visible disabilities, disclosure and being an 'insider' in disability research and 'other' in the disability movement and academia" en Ableism in Academia: Theorising experiencies of disabilities and cronic illnesses in higher education editado por Brown, N. y Leigh, J. UCL Press: London.

Goffman, E. (1963) Stigma: Notes on the Management of a Spoiled Identity. Englewood Cliffs: Prentice Hall.

Humeres, M. (2016). "Hacia una genealogía del 'niño símbolo'" En: (Des)Orden de Género. Políticas y mercados del cuerpo en Chile. Santiago: CRANN Editores. Pp. 279-298.

Liegh J. y Brown, N. (2020) "Internalised ableism: Of the political and the personal" en Ableism in Academia: Theorising experiencies of disabilities and cronic illnesses in higher education editado por Brown, N. y Leigh, J. UCL Press: London.

Martin, N. (2020) "A practical response to ableism in leadership in UK higher education" en Ableism in Academia: Theorising experiencies of disabilities and cronic illnesses in higher education editado por Brown, N. y Leigh, J. UCL Press: London.

Mella, S., Díaz, N., Muñoz, S., Orrego, M., y Rivera, C. (2014). "Percepción de facilitadores, barreras y necesidades de apoyo de estudiantes con discapacidad en la Universidad de Chile". Revista Latinoamericana de Educación Inclusiva, Vol. 8, $\mathrm{N}^{\circ}$ 1. Pp. 63-80.

Naciones Unidas. (2006). Convención Sobre los Derechos de las Personas Con Discapacidad.

Naciones Unidas. (2016). Convención sobre los derechos de las personas con discapacidad: Observaciones finales sobre el informe inicial de Chile.

Oliver, M. J. (1998). "¿̇na sociología de la discapacidad o una sociología discapacitada?" En: Barton, Len (Comp.) Discapacidad y Sociedad. Madrid, Morata. Pp. 34-58.

Oliver, M. J. (1999) "Capitalism, disability and ideology: A materialist critique of the Normalization principle". Conference Paper, A quarter-century of normalization and social role valorization: evolution and impact; 1994; Ottawa University of Ottawa Press, pp 163-174 
Opazo, C., Kalawski, A., Grass, M. (2019) "Quinta Parte. Nota introductoria" en Democracias incompletas: debates críticos en el cono sur. Editado por Blanco, F. y Opazo, C. Editorial Cuarto Propio: Santiago.

Organización Mundial de la Salud; Banco Mundial. (2011). Informe Mundial sobre la Discapacidad.

Palacios, A. (2008). El modelo social de discapacidad: orígenes, caracterización y plasmación en la Convención Internacional sobre los Derechos de las Personas con Discapacidad. Madrid: Grupo Editorial CINCA.

Palacios, A., y Romañach, J. (2006). 2. "El peso de la historia: La evolución de los modelos de la diversidad funcional". En: El modelo de la diversidad. La bioética y los Derechos Humanos como herramientas para alcanzar la plena dignidad en la diversidad funcional. Madrid, Ediciones Diversitas. 37-64.

Parchomiuk, M. (2014) "Social context of disabled parenting". Sexuality and Disability, Vol. 32, pp. 231-242, DOI 10.1007/s1 1195-014-9349-5

Romañach, J., y Lobato, M. (2005). "Diversidad funcional, nuevo término para la lucha por la dignidad en la diversidad del ser humano". Foro de Vida Independiente, $1-8$.

Salinas, M., Lissi, M.-R., Medrano, D., Zuzulich, M.-S., y Hojas, A.-M. (2013). "La inclusión en la educación superior: desde la voz de estudiantes chilenos con discapacidad". Revista Iberoamericana de Educación, Vol. 63, №63, pp. 77-98.

Servicio Nacional de la Discapacidad. (2016). Libro Resultados II Estudio Nacional de la Discapacidad. Recuperado el 26/10/2017 de: http://observatorio.ministeriodesarrollosocial.gob.cl/endisc/docs/Libro_Resultados_Il_Estudio_Nacional_de_la_ Discapacidad.pdf

Valenzuela, B. (2016). Tesis Doctoral La inclusión de estudiantes con discapacidad en educación superior chilena, factores favorecedores y obstaculizadores para su acceso y permanencia.

Zuzulich, S., Salinas, M., Achiardi, C., Hojas, A. M., y Pedrals, N. (2009). Discapacidad en contextos universitarios: Experiencia del PIANE UC en la Pontificia Universidad Católica de Chile. Calidad En La Educación, 307(30), 305-324. Recuperado el 24/05/2018 de: http://search.ebscohost.com/login.aspx? direct=trueydb=eveyAN=44087708ysite=ehost-live

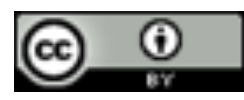

Este es un artículo de acceso abierto bajo licencia Creative Commons Reconocimiento 4.0 Internacional 